\title{
IMPROVEMENT OF EFFICIENCY OF PV PANELS FOR WATER HEATING BY CHANGING HEATER RESISTANCE
}

Ilze Pelece, Imants Ziemelis, Henriks Putans, Andrejs Snegovs

Latvia University of Life Sciences and Technologies, Latvia

ilze.pelece@1lu.lv,imants.ziemelis@1lu.lv, henriksooo@inbox.lv, andrejs.snegovs@gmail.com

\begin{abstract}
The main use of solar energy in Latvia is for water heating in solar collectors. But solar energy can be used for heating of water or air not only with solar collectors, but also with photovoltaic (PV) panels. Here electrical heaters have been used; from the electro-technical viewpoint they are of active resistance with power factor $\cos \phi=1$. Such kind of water heating has some advantages in comparison with solar collectors. In case of solar collectors heating goes on only when the temperature of the heat carrier exceeds that of the heated water, therefore, the efficiency of heating strongly depends on the temperature of the heated water. Power of the electric heater does not depend on the temperature of the water. In case of solar collectors heated water (or heat carrier) must be transported at rather a large distance from the collector to the place where the heated water is used, leading to large heat loss. In case of PV panels the electric energy has been transported with much less loss. Because of non-linear load curves of PV panels and dependence of the shape of the curve on solar irradiance and the air temperature, the energy received from the panel depends on the resistance of the heater. Traditionally voltage converters with the function of searching of point of maximal power have been used. Such converters are very expensive. Therefore, we propose to use constant resistance with the value appropriate to the used PV panel and to the mean weather conditions and solar irradiance. Measurements of heating of water have been done. It is found that the lower the solar irradiance, the larger resistance gives better results. In our situation the load resistance $4.6 \Omega$ gives the best results, while from the producer's information at high solar irradiances $3.8 \Omega$ load resistance is the best.
\end{abstract}

Keywords: solar energy, photovoltaic, water heating, efficiency.

\section{Introduction}

Photovoltaics (PV) or solar cells are devices for transforming of direct solar energy into electric one. PV technologies are rapidly developing in recent years [1;2].

Traditionally PV technologies are used for producing of electricity, but for producing of heat solar collectors are used. But there are economic branches, in which solar cells are used for heat production. For example, when heating the air, drying the agricultural produce, or maintaining the premises microclimate, or for heating water that would be used for economic purposes. When heating water or air, solar panels (photovoltaics) have an active load with a power factor $\cos \varphi=1$.

Because of the non-linear volt-ampere curve of the solar panel, its power is very dependent on the load resistance [3;4]. These curves are dependent also on solar irradiance and on the temperature of the panel. In order to obtain the largest amount of energy from solar panels, they are connected to a voltage converter with the point of maximal power search function. Such converters are expensive in comparison with the rest of the equipment, because they cost several hundred euros, or for powerful systems even thousands of euros. Therefore, possibilities are searched for direct connecting of the solar panel with a load, which, by choosing the load active resistance value, ensures a sufficiently high power output.

\section{Materials and methods}

Photovoltaic (PV) panels Solet 60.6-WF-250 have been studied in this article. The experiments have been carried out on the roof of the Ulbroka Scientific Centre. Four panels are used with four different load resistances: 3.6, 4.6, 6.6 and $8.4 \Omega$. The panels are mounted stationary at a tilt angle of $40^{\circ}$ to the horizon (Fig. 1). The main parameters of the panel are given in Table 1.

Main parameters of solar panel Solet 60.6-WF-250

\begin{tabular}{|l|l|}
\hline Parameter & Value \\
\hline Maximal power $P_{\max }$ & $255 \mathrm{~W}$ \\
\hline Voltage at maximum power point $V_{M P P}$ & $30.9 \mathrm{~V}$ \\
\hline Open voltage, $V_{o c}$ & $38.4 \mathrm{~V}$ \\
\hline
\end{tabular}


Table 1 (continued)

\begin{tabular}{|l|c|}
\hline \multicolumn{1}{|c|}{ Parameter } & Value \\
\hline Current at maximum power point $I_{M P P}$ & $8.06 \mathrm{~A}$ \\
\hline Short circuit current $I_{s c}$ & $8.6 \mathrm{~A}$ \\
\hline Thermal coefficient of power & $(-0.47) \% \cdot \mathrm{K}^{-1}$ \\
\hline Size & $1640 \times 992 \times 45 \mathrm{~mm}$ \\
\hline Mass & $22 \mathrm{~kg}$ \\
\hline Energy conversion ratio & $15 \%$ \\
\hline
\end{tabular}

From the values given in Table 1 the optimal value of the load resistance at optimal conditions can be calculated:

$$
R=\frac{U_{M P P}}{I_{M P P}}=\frac{30.9}{8.06}=3.83 \Omega,
$$

where $U_{M P P}-$ voltage at maximum power point, $\mathrm{V}$;

$I_{M P P}$ - current at maximum power point, $\mathrm{A}$;

$R$ - load resistance, $\Omega$.

This calculation gives the optimal value of the load resistance $3.83 \Omega$ for one panel. But such value of resistance would be optimal at optimal conditions; in real conditions (irradiance and panel temperature) the optimal value would be different.

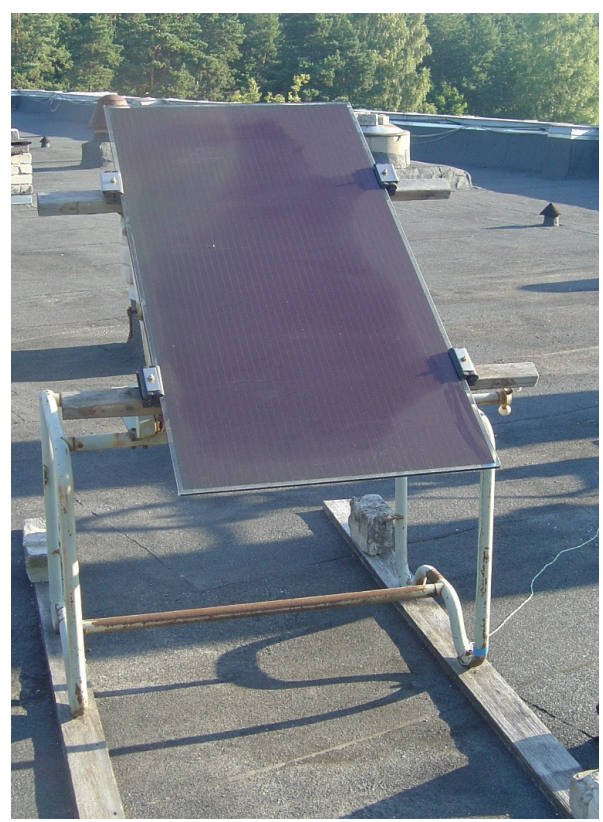

Fig. 1. Solar panel

Figure 2 shows the power-voltage curve of the panel Solet P60.6 - 250. It must be taken into account that the open circuit voltage depends only on solar irradiance, but this figure shows the real voltage drop on the load resistance and therefore depends also on the resistance.

As it can be seen from the graph, this dependence is valuable at large voltage values, above the maximal power point. It means that with large values of the resistance the power will drop significantly.

In case of stationary mounted panels, the efficiency is very hard to evaluate, if direct radiation has not been measured. In our case the global solar energy was measured using the ISO 1-sth class pyranometer CMP 6 from Kipp\&Zonen. The measured values were registered automatically after every 5 minutes.

Therefore, the ratio of the energy produced by $1 \mathrm{~m}^{2}$ of the panel to that received from the sun by $1 \mathrm{~m}^{2}$ of the horizontal surface (effectiveness [5]) was used instead of the efficiency. This ratio depends 
on the efficiency of the panel and on positioning (tilt angle) of it [5]. As all panels in our experiment are positioned equally, such ratio can be used for comparing them.

Measurements were carried out from 12 of May 2018 till 15 of August. Only full days were taken into account, therefore the results are from 70 days.

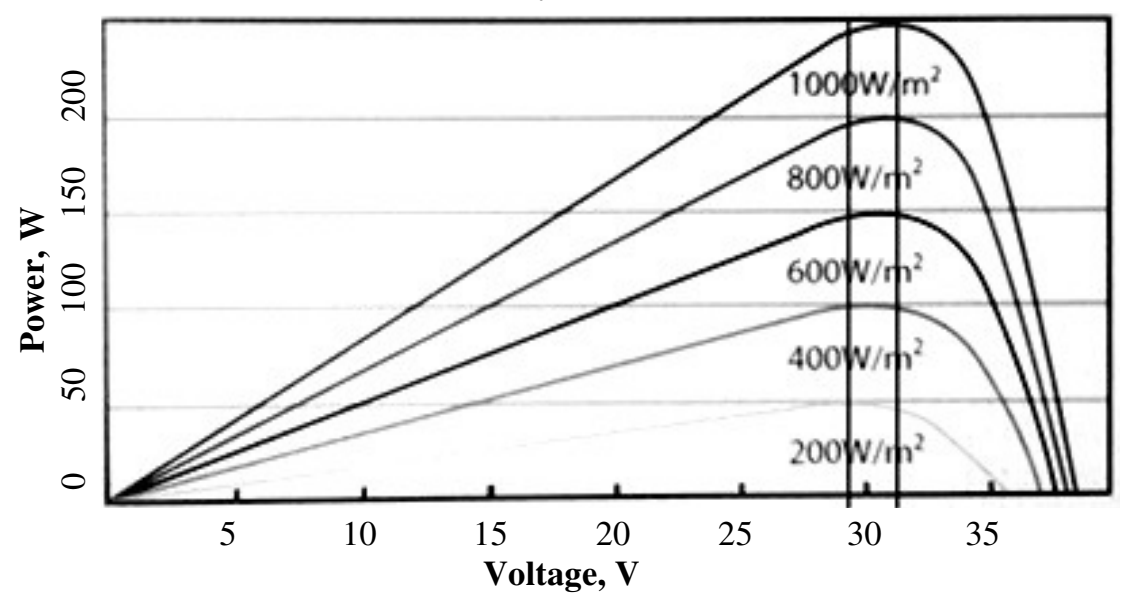

Fig. 2. Power-voltage curve of PV panel (Producer's information)

As the instantaneous values are affected by inertia and other circumstances, the daily energy sums were used.

Daily sum of solar energy received by $1 \mathrm{~m}^{2}$ of horizontal surface is calculated as:

$$
E_{s}=\sum I \cdot \Delta t / 3.6 \cdot 10^{6},
$$

where $E_{s}$ - received solar energy, $\mathrm{kWh}$;

$I$ - global irradiance, $\mathrm{W} \cdot \mathrm{m}^{-2}$;

$\Delta t$ - time interval between the measurements, $\mathrm{s}$.

As load resistance electric heaters with resistances $3.6 \Omega, 4.6 \Omega, 6.6 \Omega$ and $8.4 \Omega$ were used. The heaters were placed in 301 plastic non-isolated water reservoirs. Than the power can be calculated as:

$$
P=\frac{U}{R^{2}},
$$

where $P$-power, $\mathrm{W}$;

$U$ - voltage, $\mathrm{V}$;

$R$ - resistance, $\Omega$.

After every 6 min the voltage on these resistances was measured. Such interval of $360 \mathrm{~s}$ allows to calculate the daily sum of energy produced by $1 \mathrm{~m}^{2}$ of the panel surface, in $\mathrm{kWh}$, by simple formula:

$$
E_{C}=\sum P /(S \cdot 10000) \text {, }
$$

where $E_{C}$ - energy sum, $\mathrm{kWh}$;

$P$ - power, W;

$S-$ area of the panel, $\mathrm{m}^{-2}$.

Effectiveness of the panel can be calculated as:

$$
e=\frac{E_{C}}{E_{S}} .
$$

If we have plotted the dependence of the collector's daily energy sum $E_{C}$ on that of solar energy $E_{S}$ and drawn the linear trend line

$$
y=A \cdot x+B,
$$


then the slope A of the trendline is the effectiveness of the collector. Accuracy of these coefficients can be calculated as shown, for example, in [6].

\section{Results and discussion}

Characteristic daily course of the power produced by the PV panel with different load resistances at partly sunny day (11 of July, 2018) is shown in Fig. 3.

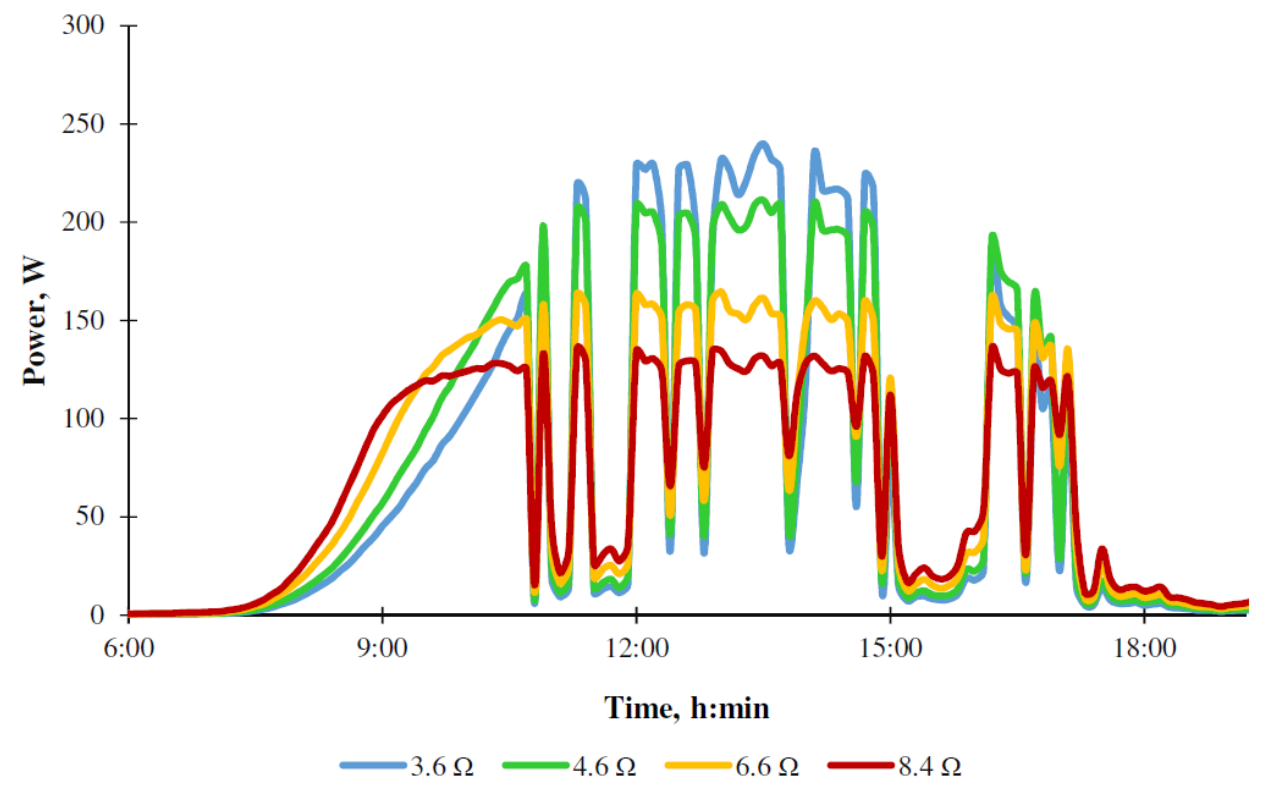

Fig. 3. Daily course of power produced by PV panels with different load resistances (11 of July, 2018)

We can see from this graph that at large values of solar irradiance the panel loaded with $3.6 \Omega$ resistance gives almost nominal panel's power, $250 \mathrm{~W}$, while that loaded with $8.4 \Omega$ resistance gives only approximately half of that. But when irradiance is small, the situation is opposite. In the morning of a sunny day (and also in the evening) the panel loaded with the highest resistance gives maximal energy almost an hour longer. Also, when irradiance decreases because of clouds, the largest load resistance gives better results.

Figure 4 shows the dependence of the daily energy gain from the PV panel with different load resistances on the daily sum of solar energy on horizontal surface.

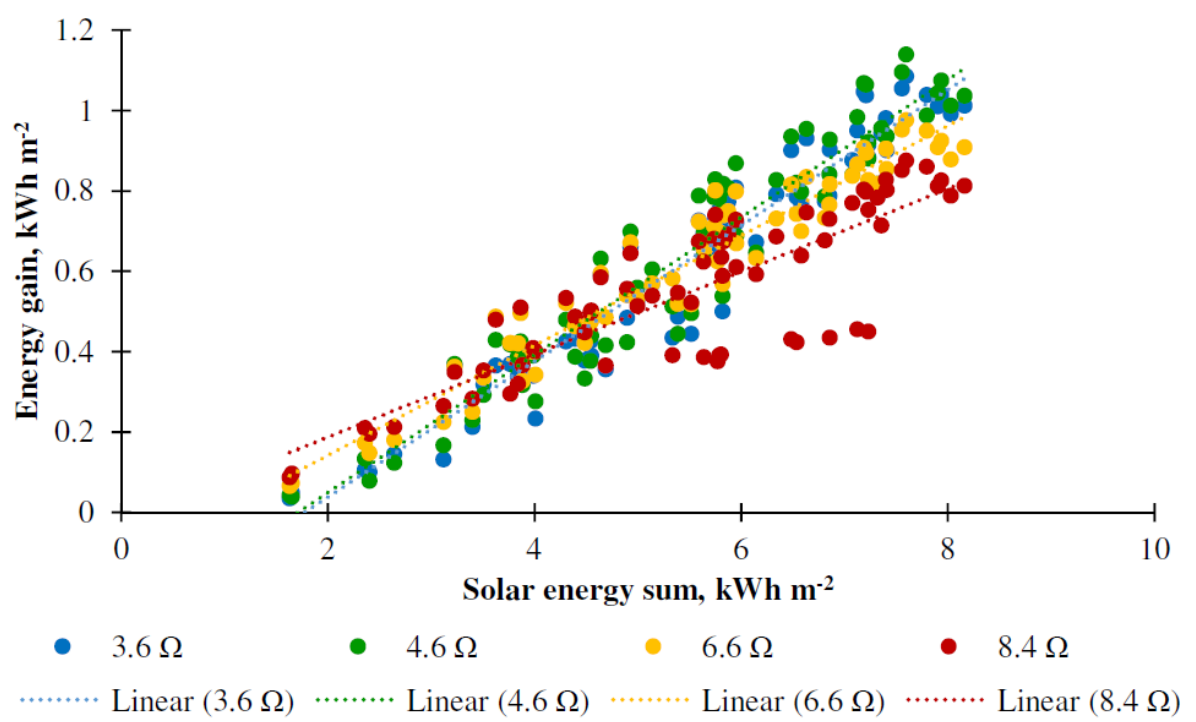

Fig. 4. Dependence of energy gain from PV panel with several load resistances on solar irradiance 
Here the daily energy sums calculated from formulae (2) and (4) are plotted. Therefore, the slope of the linear trendline in the graph characterises the effectiveness of conversion of solar energy.

Coefficients A and B in this equation for different load resistances, as well as determination of the coefficient $R^{2}$ of the trendline, are shown in Table 2. Here is shown also the total energy sum obtained in all period of the experiment for each resistance.

Table 2

Trendline slope, intercept, determination coefficient and total energy sum

\begin{tabular}{|c|c|c|c|c|}
\hline Resistance, $\boldsymbol{\Omega}$ & Slope, $\mathbf{A}$ & Intercept, $\mathbf{B}$ & Determination $\mathbf{R}^{\mathbf{2}}$ & Energy sum, kWh \\
\hline 3.6 & $0.169 \pm 0.033$ & $-0.2999 \pm 0.0058$ & 0.93 & 44.293 \\
\hline 4.6 & $0.171 \pm 0.037$ & $-0.2926 \pm 0.0065$ & 0.91 & 45.657 \\
\hline 6.6 & $0.137 \pm 0.025$ & $-0.1308 \pm 0.0044$ & 0.93 & 43.624 \\
\hline 8.4 & $0.103 \pm 0.044$ & $-0.0179 \pm 0.0078$ & 0.72 & 38.497 \\
\hline
\end{tabular}

The highest slope, i.e. the highest effectiveness is obtained for $4.6 \Omega$ resistance. Also the total sum of energy obtained in all period of the experiment is the highest for $4.6 \Omega$ resistance. Smaller intercept for higher resistances illustrates better suitability of the highest resistance for smaller solar irradiances.

Further studies of dependence of the obtained power by several load resistances on instant solar irradiance would be interesting. For that, good synchronization of the measuring devices is necessary, and also information on inertia of the solar panel.

\section{Conclusions}

1. Load resistance calculated from voltage and current at the maximal power point is optimal only for optimal solar irradiance and other factors.

2. At lower irradiances higher resistance load gives more energy gain, but dependence in details must be studied further.

3. In our experiments resistance $4.6 \Omega$ gave the greatest energy gain, while from the producer's information $3.8 \Omega$ load resistance must be optimal.

\section{References}

[1] Kondo M, Matsuda A. Novel aspects in thin film silicon solar cells-amorphous, microcrystalline and nanocrystalline silicon. Thin Solid Film, vol. 457, 2004, pp. 97-102.

[2] Yamamoto K., Nakajima A., Yoshimi M., et al. A high efficiency thin film silicon solar cell and module. Sol Energy, vol. 77, 2004, pp. 939-949.

[3] Lin J., Liao T., Lin B. Performance analysis and load matching of a photovoltaic-thermoelectric hybrid system. Energy Conversion and Management, vol. 105, 2015, pp. 891-899.

[4] Li G., Zhou K., Song Z., Zhao X., Ji J. Inconsistent phenomenon of thermoelectric load resistance for photovoltaic-thermoelectric module. Energy Conversion and Management, vol. 161, 2018, pp. 155-161.

[5] Pelece I., Shipkovs P. Theoretical and experimental investigations of cylindrical air-heating solar collector. Latvian Journal of Physics and Technical Sciences, vol. 53, iss. 3, 2016, pp. 11-21.

[6] Arhipova I., Bāliņa S. Statistika ar Microsoft Excel ikvienam. (Statistics with Microsoft Excel for everyone) Rīga: Datorzinību centrs, 1999-2000. 2 d. ISBN 9984665038. (In Latvian) 